\title{
Molecular medicine in development
}

The case for modernizing the practice of medicine in the developing countries of the world is strong and also irresistlble, but the mechanisms for doing that need to be improved.

Oxford. What can rich countries do to improve the quality of biomedical science in the rest of the world? That question occupied an absorbing two-day meeting in Oxford last week at which a score of academics from developing and (mostly) semideveloped countries set out their shopping lists. The gathering was organized by the Oxford International Biomedical Centre, intended as a kind of intellectual brokerage and which is the creation of cell biologist Professor Charles Pasternak of St George's Medical School in London. (The Oxford connection consists chiefly of Pasternak's wish eventually to erect a building on a site he has identified.)

What follows is not so much a report of the proceedings as an account of some of the issues that arose, often implicitly, from what people said about the problems of teaching medicine and delivering health care in countries such as China, India, Kenya, Poland and those of Latin America.

One central issue is the extent to which the medical curriculum, and the pattern of research, should take account of the past few decades of understanding gathered by molecular biologists. Lu Shen Dong, a vicepresident of the Chinese Academy of Medical Sciences, asserted that gene therapy now stands alongside traditional Chinese medicine in the country's 131 medical schools. Most other participants were alarmed that their systems would be deprived of therapeutic opportunities by the concentration of modern biology in the rich countries of the world.

But why invest money and energy in learning the most up-to-date techniques when the principal causes of death and disability can be traced to old-fashioned causes, preventable infections and public hygiene? The question echoes the arguments in the 1960s about India's wisdom in investing expensively in the development of nuclear energy, when the country's economic and social problems had more familiar causes. (India may not have benefited much from nuclear energy as such, but the recent success of its chemical and electronic industries are identifiably by-products of the original development.)

Last week's gathering was in no doubt that modern techniques in biology must find their way into medicine everywhere, and quickly. For one thing, new techniques may help shed present burdens of morbidity, as hepatitis- $B$ vaccine may reduce the incidence of liver cancer. But the general case for including modern medicine in the curriculum is the career life expectancy of physicians, who will be working with patients for decades ahead. According to Professor Maciej Nalecz, director of the Nencki Institute of Experimental Biology in Warsaw, one of Polish medicine's most urgent needs is to retrain the physicians already at work in hospitals.

Nalecz also had a cheerful tale to tell about the establishment in Warsaw of an International Centre for Cell and Molecular Biology, jointly financed by UNESCO and the Polish government, and due to open this October. He regards this both as a means by which professionals at all levels can be given some training in molecular medicine and a way of drawing other Central European countries into collaborative research programmes.

In some respects, the new centre is modelled on the European Molecular Biology Laboratory in Heidelberg, but there will be no hard core of permanent staff; instead, researchers will be employed on three-year fellowships. Management will be by a steering committee on which participating countries will be represented. If the new centre makes a good start, there is every reason for Nalecz's belief that Poland has a model research centre that might meet some of the needs of other regions of the world, Latin America for example.

Curious as it may seem, Slovenia (represented by Professor Vito Turk of the J. Stefan Institute at Ljubljana), only recently the most northern part of Yugoslavia, is more self-confident, perhaps because its economy rests on substantial pharmaceutical and electronic industries (as well as on agriculture). The plea by Professor Arnost Kotyk, from the Institute of Physiology at Prague, that Central Europe should worry about the poor salaries paid to people working in research was widely welcomed, not simply by those from the region.

That is one of the well-springs of another insistent theme last week: the steady loss of trained people from developing and semideveloped countries. Lu, for example, said that of 2,000 physicians sent for specialist training overseas by China in the past 10 years, only 1,000 had so far returned. Dr Rem Petrov, an immunologist who is also a vice-president of the Russian Academy of Sciences, appeared more sanguine about the loss of people from Russian institutes, estimating it at about 10 per cent by emigration (and rather more by the loss of people to other activities); he did not remark on the circumstance that the brightest are the first to leave.

So what is to be done about the brain drain'? One speaker held that it is "immoral" for rich countries to recruit poor countries' skill in the deliberate way in which (some alleged) they do. The counter view is that it would be an intolerable intrusion on the personal liberty of researchers that they should be prevented from moving countries, but that it is only prudent that governments looking for further training for their specialists elsewhere should prudently skew the terms in such a way that their people eventually return. That, of course, is one respect in which Kotyk's opinion about the pay of researchers will in the end be telling.

The problems of the truly poor countries were not much advertised last week; they were not represented. But India (which is two countries, one rich and one poor, with the former growing quickly) produces 17,000 qualified physicians a year, but still cannot provide for the health needs of the rural poor. It is the same in South Africa: Dr Chris Hugo-Hamman, a member of the South African delegation to the European Union, said that there are 1,200 people for every physician in the white communities, but 12,000 to one in the black communities. The "crisis" in South Africa's education, he said, is that only 1 out of 316 black students finds his or her way to a university.

Kenya seems even worse off. Joseph Ruto, the high commissioner for Kenya in London, said that there are insufficient funds for health care and for running the medical schools and that the country is once again assaulted by malaria and tuberculosis as well as by HIV. Dr Baldip Khan of the Kenyan Medical Research Centre at Kemri, whose own field is the search for antigens effective in developing vaccines against schistosomiasis, told a moving tale of the sense of isolation she shares with 39 colleagues and of the encumbrance of having to walk for half an hour to read immunoassays in another building.

What is the rest of the world doing to help? The UNESCO centre in Warsaw is something to boast about. Otherwise, there is a plethora of fellowship and scholarship schemes. The Oxford centre is pushing for a standardized one-year fellowship scheme for medically qualified people. An equally important need is some way of simplifying and making uniform the schemes that exist already, many of which appear to be underused, probably for lack of information.

John Maddox 